Fanum

Sociológico
Forum Sociológico

Série II

$38 \mid 2021$

Número 38

\title{
Retratos sociais do quotidiano de homens com 80 e mais anos
}

Everyday social portraits of men aged 80 and over

Maria João Bárrios e Cláudio Faustino

\section{OpenEdition \\ 12 Journals}

Edição electrónica

URL: https://journals.openedition.org/sociologico/9723

DOI: $10.4000 /$ sociologico. 9723

ISSN: 2182-7427

Editora

CICS.NOVA - Centro Interdisciplinar de Ciências Sociais da Universidade Nova de Lisboa

\section{Edição impressa}

Paginação: 35-44

ISSN: 0872-8380

Refêrencia eletrónica

Maria João Bárrios e Cláudio Faustino, «Retratos sociais do quotidiano de homens com 80 e mais anos», Forum Sociológico [Online], 38 | 2021, posto online no dia 02 junho 2021, consultado o 29 março 2022. URL: http://journals.openedition.org/sociologico/9723 ; DOl: https://doi.org/10.4000/ sociologico.9723 


\section{RETRATOS SOCIAIS DO QUOTIDIANO DE HOMENS COM 80 E MAIS ANOS \\ EVERYDAY SOCIAL PORTRAITS OF MEN AGED 80 AND OVER}

DOI: https://doi.org/10.4000/sociologico. 9723

\section{Maria João Bárrios}

Universidade de Lisboa, Instituto Superior de Ciências Sociais e Políticas, Centro de Administração e Políticas Públicas, Lisboa, Portugal. ORCID: https://orcid.org/0000-0002-4569-9770

Cláudio Faustino

Investigador independente, Lisboa, Portugal. ORCID: https://orcid.org/000-0002-6549-027X

\section{Resumo}

O processo de envelhecimento suscita alterações nas rotinas diárias e familiares. Viver mais anos exige que se considerem essas implicações nas fases mais avançadas, contemplando dificuldades e necessidades à medida que a vulnerabilidade aumenta.

Esta pesquisa centrou-se num conjunto de homens $80+$, em contexto urbano (município português de Odivelas), objetivando identificar e analisar as suas estratégias de ocupação do tempo e participação social. Foi realizado um inquérito por entrevista e efetuado o mapeamento dos roteiros relativos à utilização de serviços e recursos, através do software ArcGIS.

Verificámos que os níveis de participação social e a perceção do processo de envelhecimento eram condicionados por hábitos, rotinas e práticas individuais ao longo da vida ativa. Os inquiridos com práticas saudáveis, que mantêm os índices de participação social, revelam uma manutenção dos objetivos, encaram o futuro com otimismo e efetuam uma melhor autoavaliação da saúde. Por sua vez, a rede formal/informal, as condições habitacionais e a deslocação por meios próprios levam a uma maior autonomia e independência.

Palavras-chave: Envelhecimento masculino, participação social, longevidade

\section{Abstract}

The ageing process brings changes capable of transforming daily and family routines. Living longer requires considering these implications in the most advanced phases, difficulties and needs, as vulnerability increases.

This research focused on a population of men aged $80+$, in an urban context (Portuguese municipality of Odivelas). The objective was to identify and analyze their strategies for occupying time and social participation. We have conducted an interview survey and we have mapped the roadmaps related to the use of services and resources, using the ArcGIS software.

Social participation levels and perception of the ageing process were conditioned by habits, routines and individual practices throughout active life. The respondents with healthy practices, who maintain the levels of social participation i) revealed the maintenance of the objectives; ii) face the future with optimism; and iii) perform a better self-assessment of health. The formal/ informal network, housing conditions and own means to travel lead to greater autonomy and independence.

Keywords: ageing of male, social participation, longevity 


\section{Introdução}

O envelhecimento da população portuguesa acompanha as tendências da dinâmica do envelhecimento no contexto dos países europeus, em que se integra. $O$ envelhecimento dentro do envelhecimento é um dos aspetos que caracterizam essas populações. Dentro do crescimento da proporção de pessoas idosas $^{1}$, o grupo de indivíduos muito velhos (80+) foi o que cresceu mais rapidamente ${ }^{2}$. De acordo com as projeções do Eurostat, as pessoas com 80 e mais anos representarão $7.22 \%$ da população europeia em 2030, acentuando o envelhecimento no topo da pirâmide etária.

As diferenças de esperança de vida (EV) evidenciam a importância do género na longevidade. Os dados do Eurostat de 2018 mostram que, em Portugal, a EV à nascença para as mulheres era de 84.5 anos, acima da UE28 (83.6 anos), sendo o quarto valor mais alto. Já do lado dos homens, a EV à nascença era de 78.3 anos, o mesmo valor da UE28. Homens e mulheres diferem em EV ao longo da vida, havendo uma discrepância considerável na capacidade de sobrevivência de ambos os sexos (Fernandes \& Burnay, 2019). Fernandes (2008) refere que há nos homens uma propensão para hábitos e comportamentos de risco associados que diminui a sua EV, atenuada apenas pela condição socioeconómica, que induz a uma melhor capacidade física por parte dos indivíduos muito idosos. Um estudo de Fernandes et al. (2012), realizado a partir do INS $2005 / 6$, concluiu que a visão veiculada e aceite de que os homens recorrem com menor frequência aos cuidados de saúde relaciona-se com os padrões de masculinidade, ligados à representação social de que estes suportam qualquer dor e incapacidade. Fernandes e Burnay (2019) acrescentam que, ao longo do ciclo de vida, os homens estão mais expostos a conflitos, utilizando estratégias e práticas de maior agressividade na resolução de problemas, com riscos acrescidos (incluindo o suicídio). Por outro lado, eles estão em vantagem no acesso à educação e aos bons empregos, com consequentes rendimentos mais altos e menor vulnerabilidade à pobreza, refletindo-se em condições de saúde diferentes das mulheres (Fernandes \& Burnay, 2019).

No entanto, se por um lado as mulheres vivem mais tempo, por outro temos assistido a um aumento da EV masculina. De 2006 para 2018, a EV à nascença cresceu 2.8 anos para os homens portugueses (mais que o crescimento na UE28, de 2.4 anos) e 2 anos para as mulheres portuguesas (também superior ao crescimento na UE28, de 1.7 anos) (Eurostat).

Mas as diferenças de género, em particular as conquistas masculinas, estendem-se ainda à EV em boa saúde. Segundo os dados do Eurostat, em 2018 as mulheres portuguesas tinham uma EV de
84.5 anos, mas apenas viviam saudáveis 57.5 anos, correspondendo a $68 \%$ da sua EV. Já os homens portugueses, apresentavam uma EV à nascença inferior à das mulheres, de 78.3 anos, mas viviam um maior número de anos com saúde, 59.8 anos, correspondendo a $76 \%$ da sua EV. As desigualdades na EV e nas condições de saúde entre homens e mulheres ao longo da vida têm sido explicadas por desigualdades biológicas, psicológicas e sociais. Por oposição às diferenças entre os sexos, as diferenças de género podem ser evitáveis e relacionam-se com o papel social ou com a discriminação (Fernandes \& Burnay, 2019).

As mudanças demográficas e sociais, acompanhadas pela melhoria do estado de saúde das populações, criaram novas e distintas realidades para homens e mulheres. Os ciclos de vida afastaram-se das classificações padronizadas e das transições bem definidas das últimas décadas, perfilando-se cada vez mais longos e mutáveis (Fernandes, 2016). Com todas as oportunidades, o aumento da EV também expressa implicações ao longo do ciclo de vida, em particular na fase mais avançada, ao instalar desafios inerentes ao envelhecimento biológico, com efeitos nas condições de vida dos homens mais velhos. Estes desafios emergem da redução da funcionalidade nas idades mais avançadas, podendo levar a limitações, incapacidade e dependência, através da instalação de quadros de fragilidade e comorbilidade.

As conquistas de EV dos homens portugueses, com o consequente aumento do número de sobreviventes com 80 e mais anos, conduzem à pertinência da análise das suas condições de envelhecimento. Estas dependem dos recursos pessoais, mas também das características do ecossistema onde os homens envelhecem, bem como dos recursos sociais que têm à sua disposição. Este artigo é o resultado de uma pesquisa que parte da autonomia e do empowerment ao longo do processo de envelhecimento, incidindo nos homens que atingem idades mais avançadas. Definiu-se, assim, como objetivo geral caracterizar um conjunto de homens com 80+ anos, de modo a identificar e analisar as suas estratégias de ocupação do tempo e participação social, reconstituir os roteiros relativos à utilização de serviços e recursos, num ecossistema urbano, no sentido de identificar as necessidades de ajuste das pessoas cuja vulnerabilidade aumenta.

\section{Desafios do envelhecimento na perspetiva de género}

Ao nível biológico, os desafios do crescimento da EV estão relacionados com a progressiva deterioração dos organismos, que se instala em termos de redução da funcionalidade física e/ou cognitiva. Por funcionalidade entende-se todas as funções do corpo, atividades e participação, que dependem da 
interação do indivíduo com os fatores contextuais. Se esta interação for negativa, a redução da funcionalidade poderá levar a incapacidade, que compreende as alterações nas estruturas, as limitações das atividades e as restrições da participação (Fontes et al., 2013). Neste sentido, as pessoas mais velhas são mais suscetíveis a doenças crónicas (Budib et al., 2020), necessitando de serviços e cuidados adequados.

Residem aqui os desafios impostos às políticas de saúde que priorizam o envelhecimento da população, considerando as alterações da estrutura familiar (Bárrios, 2017). Estes desafios estendem-se ao acesso a serviços e equipamentos de apoio social (Quaresma, 2004). Este repto reforça a importância de dirigir a atenção para a participação das pessoas à medida que envelhecem, criando respostas locais que aumentem as oportunidades de participação social, cultural, educacional e ocupacional, passíveis de se enquadrar no paradigma de "active ageing" (WHO, 2002). Entende-se ainda que este paradigma também se aplica às pessoas mais frágeis e com incapacidade, considerando o aumento da heterogeneidade à medida que a idade avança (Bárrios et al., 2020). Trata-se da promoção da manutenção/ integração social e, por oposição, da prevenção da exclusão social/perda de papéis sociais, pois grande parte das pessoas mais velhas deseja participar na vida social com autonomia (Bárrios et al., 2020).

Estes desafios implicam uma adaptação dos apoios informais e das organizações formais, que atuam numa rede regional e nacional (Fernandes \& Botelho, 2007). O processo de envelhecimento não deve ser pensado numa lógica coletiva, de grupo homogéneo. A população dita "idosa" caracteriza-se pela heterogeneidade social e económica construída ao longo de diferentes percursos, em espaços socias diferenciados. Os recursos sociais, como a origem social, os diplomas escolares, as orientações e sucessos profissionais, constituem fatores de diferenciação cujo impacto ao longo da vida se traduz em muito diferentes condições sociais culturais e económicas, que afetam a forma como se envelhece e os recursos de que se dispõe (Fernandes, 2004).

$\mathrm{Em}$ idades avançadas, mulheres e homens apresentam variadas situações de vulnerabilidade, tendo em conta os seus papéis sociais e culturais, bem como o nível de proteção institucional oferecido pela sociedade (Figueiredo et al., 2007). São os homens os principais afetados com a perda do papel social e com as mudanças abruptas que a transição para a reforma acarreta (Fernandes \& Burnay, 2019). Com a passagem à reforma, os homens tendem a isolar-se da sociedade ou a não serem tão participativos como eram em atividade, ao limitarem os seus contactos à rede informal de amigos/família. Em muitas situações, a família mais próxima também é afetada por este desânimo e alteração substancial das rotinas, o que vem confirmar a distância dos laços que já tinham com os filhos. O enquadramento social, muitas vezes reduzido aos membros da família, juntamente com as características psicológicas, constituem assim as principais determinantes do envelhecimento no género masculino (Fernandes \& Botelho, 2007; Fernandes et al., 2009).

Por apresentarem uma maior probabilidade de perder familiares e amigos, as pessoas mais velhas estão mais vulneráveis à solidão e ao isolamento social. Esta condição não afeta de igual forma homens e mulheres, na medida em que existem mais mulheres viúvas e estas possuem na generalidade características de maior sociabilidade do que os homens (Fernandes, 2008; ILC-BR, 2015; Waite, 2004; WHO, 2002). O isolamento ou a perda de objetivos, no caso de divórcio ou viuvez, deixa os homens mais velhos entregues a si próprios e com baixos níveis de autonomia (Daniel et al., 2012).

Estas considerações assumem uma dimensão maior perante os desafios sociais decorrentes dos termos depreciativos associados aos mais velhos e ao isolamento social a que são vetados, considerando-os, numa perspetiva idadista, pouco úteis para a sociedade (Daniel et al., 2015). Ainda que a velhice se tenha tornado publicamente visível representando uma redução gradual da funcionalidade e, em certas situações, uma sobrecarga associada à precariedade económica dos mais velhos, o aumento da proporção de pessoas mais velhas não constitui um problema por si só (Fernandes, 1997). O combate ao idadismo, enquanto conjunto de estereótipos, preconceitos e discriminação posicionada na idade (Iversen et al., 2009), apela a perceções mais positivas dos homens mais velhos, contemplando a sua experiência e vivências (Daniel et al., 2012); mas passa também pela adequação dos espaços públicos e dos locais que as pessoas frequentam na fase mais avançada do ciclo de vida.

\section{Participação e empowerment dos homens mais velhos}

As ideias enraizadas na sociedade de que as pessoas mais velhas representam um problema a nível económico, social e familiar, são contrariadas por uma proporção crescente de indivíduos que se mantêm ativos, participantes e com objetivos pessoais presentes (Boom et al., 2011). As políticas que procuram responder aos desafios do envelhecimento demográfico encontram uma urgência em providenciar a cidadania nas idades mais avançadas, proporcionando segurança económica, solidariedade intergeracional e inclusão social (Walker, 2002), que passa pelo exercício da participação social.

Apesar de, em Portugal, os laços familiares e as relações de amizade fortalecerem a ligação 
existente entre os meios rural e urbano (Pimentel, 2001), as diferenças são significativas em termos de rendimento mensal, serviços de auxílio na doença e suporte sociofamiliar (Lopes, 2004). Os estudos inscritos na perspetiva ecológica do envelhecimento mostram que o declínio dos organismos biológicos se repercute nos processos transacionais pessoa-ambiente, com implicações no bem-estar e qualidade de vida das pessoas mais velhas (Machado, 2007). Por seu turno, as características do ambiente urbano são importantes na compreensão do processo de envelhecimento individual (Machado, 2007). Na análise da influência que o ecossistema onde se envelhece tem nos comportamentos, estilos de vida e exercício da participação das pessoas, constituem elementos importantes: i) as organizações locais e serviços disponibilizados, que permitem a participação e facilitam o acesso à saúde e a bens necessários/desejados; ii) as questões inerentes à habitação das pessoas mais velhas, analisadas em termos de condições habitacionais e de habitabilidade; e iii) o ambiente físico, espaços públicos e transportes, capazes de produzir segurança, promover comportamentos saudáveis, contactos intergeracionais e o exercício da participação na comunidade (Satariano et al., 2010).

A participação dos homens mais velhos está integrada na continuidade do exercício da cidadania, que muito se relaciona com o conceito de empowerment, numa ótica de intervenção do sujeito para fins de cidadania e justiça social (Pinto, 2012). Para que o empowerment se manifeste através da concentração do poder de decisão em cada indivíduo, é importante que se beneficie de equidade horizontal; isto é, o empowerment só ocorre se a capacitação do indivíduo não for condicionada nem limitada por elementos externos que não podem ser controlados (Pinto, 2012). Só com o pleno controlo e noção dos níveis de capacitação se pode desenvolver a totalidade da liberdade individual e da participação social/familiar (Pinto, 2012). A participação social dos homens mais velhos ocorre plenamente quando estão reunidos os elementos coletivos que possibilitam essa decisão individual. A ocupação da população mais velha é visível através da análise dos seus roteiros quotidianos e da utilização dos serviços e respostas sociais locais (Pinto, 2012).

Os anos que medeiam entre o desempenho de uma profissão e a reforma podem ser aproveitados de forma a que, numa fase posterior, se mantenham as rotinas e as atividades, ou se criem oportunidades de envolvimento em projetos distintos (Pereira, 2004). Para que a participação social seja plena, e para que ocorra a capacitação do indivíduo, é necessário reunir um conjunto de elementos como apoios sociais, habitação e mobiliário urbano, por contribuírem para a definição de roteiros quotidianos. Estes roteiros permitem a ocupação de espaços ou o recurso a respostas sociais locais, que possibilitam a continuidade de rotinas ou atividades relacionadas com os interesses individuais, a criação de momentos de convívio, a socialização entre pares e o diálogo intergeracional (Calado, 2004).

\section{Material e métodos}

Para concretizar o objetivo da pesquisa, realizámos um inquérito por entrevistas semiestruturadas a um conjunto de homens com 80 e mais anos, entre maio e novembro de 2018 , com recurso a um guião construído para o efeito a partir da literatura e do objetivo.

Foram entrevistados 18 homens com 80 ou mais anos, residentes num município selecionado, (Odivelas), disponíveis para colaborar com o estudo. A seleção dos entrevistados efetuou-se através do método "bola de neve", procurando-se inquirir homens não institucionalizados, com perfis diversificados em termos de participação e percursos de vida, e terminando quando se considerou atingir a saturação da amostra. A realização das entrevistas permitiu obter dados de caracterização dos indivíduos e informação mais aprofundada acerca das condições de vida e das dificuldades que enfrentam.

A informação recolhida através das entrevistas foi tratada de duas formas. As respostas abertas (abordagem qualitativa) foram sujeitas à técnica de análise de conteúdo, após transcrição das entrevistas, enquanto as respostas fechadas foram submetidas a uma análise estatística descritiva, através do software IBM SPSS Statistics 25. Num segundo momento de análise de dados, a partir da informação reunida, foram mapeados os percursos e roteiros mais frequentados pelos homens entrevistados, com recurso ao software ArcGIS, permitindo a sua análise geográfica.

\section{Caracterização do território selecionado}

Selecionou-se um contexto predominantemente urbano, capaz de refletir as alterações sociais e demográficas das últimas décadas na Área Metropolitana de Lisboa (AML): o município de Odivelas. Este concelho caracteriza-se por um crescimento populacional elevado e desmesurado (que ocorreu nas últimas três décadas), fragmentado na totalidade do território, quer ao nível urbanístico, quer ao nível social. De acordo com os Censos de 2011, Odivelas é o quarto concelho que mais cresceu na $A M L$, conduzindo a disparidades ao nível das freguesias, no que diz respeito à população e à habitação.

A par do crescimento, o município de Odivelas caracteriza-se por um envelhecimento populacional acentuado, que ocorreu nos últimos anos, após uma primeira fase de fixação da população jovem. A proporção de pessoas com 65 e mais anos cresceu 
4.4 pontos percentuais entre os Censos de $2001 \mathrm{e}$ de 2011 ( $11.9 \%$ e $16.3 \%$, respetivamente). Ocorreu ainda um aumento do índice de envelhecimento ${ }^{3}$ (112 idosos por cada 100 jovens em 2011) e do índice de dependência de idosos ${ }^{4}$ (11.9 em 2001 e 25.4 em 2011).

Além das características sociodemográficas, a seleção deste município teve em consideração a importância dos aspetos territoriais no exercício da participação (adequação e aptidão), enquanto pilar central do paradigma de "active ageing" (WHO, 2002), que sustenta movimentos como o "age friendly cities" (WHO, 2007). Falamos dos esforços exibidos pelo poder local na criação de "age-friendly environments", e em resultados de projetos como o de Almeida (2016a, 2016b).

\section{Apresentação e discussão dos resultados}

Os 18 homens tinham idade compreendida entre os 80 e os 90 anos, eram residentes no concelho de Odivelas, distribuídos pelas freguesias de Ramada/Caneças ( $n=4 ; 22.2 \%)$, Olival de Basto/ Póvoa de Santo Adrião $(n=5 ; 27.8 \%)$, Pontinha/ Famões $(n=4 ; 22.2 \%)$ e Odivelas $(n=5 ; 27.8 \%)$. Dos indivíduos entrevistados, 9 viviam sozinhos (50\%), enquanto $3(16.7 \%)$ viviam com os filhos. A grande maioria dos inquiridos apresentava níveis baixos de escolaridade, tendo frequentado apenas o $1 .{ }^{\circ}$ ciclo $(n=14 ; 77.8 \%)$

No que concerne à avaliação subjetiva da saúde, a maioria dos homens inquiridos efetuou uma avaliação razoável $(n=10 ; 55.6 \%)$, mas 14 $(77.8 \%)$ referiram problemas de saúde, queixando-se sobretudo de dificuldades ao nível ortopédico/reumatológico $(n=9 ; 50 \%)$, de locomoção $(n=7 ; 38.9 \%)$, pulmonar $(n=4 ; 22.2 \%)$ e cardíaco $(n=4 ; 22.2 \%)$. Constatamos, então, que a avaliação subjetiva da saúde por vezes não tinha uma correspondência lógica com as queixas apontadas. Isto é, ainda que os indivíduos revelassem uma autoperceção da sua saúde boa/razoável, apresentavam queixas e problemas de saúde que, no seu entender, afetavam a sua qualidade de vida e o seu dia a dia.

A maioria dos entrevistados $(n=10 ; 55.6 \%)$ não praticava atividade física com regularidade, justificando os hábitos sedentários com a idade, a debilidade da condição física e/ou a perda de motivação: Ia com a minha mulher à piscina e à dança, agora não tenho vontade de nada (entrevistado n. 3). Contudo, saliente-se que a prática de atividade física regular exige a ativação de recursos existentes e está igualmente dependente das características do ecossistema onde as pessoas envelhecem (Satariano et al., 2010) como: o espaço físico do bairro de residência, as condições de saúde, os meios de transporte e até a disponibilidade financeira. A influência que as características urbanas têm nas condições de vida destes homens é também revelada pelo sentimento de insegurança: A polícia passa por aqui algumas vezes, há roubos e barulho à noite (entrevistado n. 8); A rua é estreita e escura, saltam as vedações das casas e estão lá a fazer barulho, roubam as chapas da oficina (entrevistado n. 14).

A maioria dos homens $80+$ revelou que está satisfeito com a relação que tem com os seus familiares e amigos ( $n=13 ; 72.2 \%$ ) e que, quando precisa de ajuda (por exemplo para realização de tarefas domésticas ou cuidados pessoais), tem a quem recorrer $(n=17 ; 94.4 \%)$. Por outro lado, 38.9\% $(n=7)$ não têm ninguém com quem falar quando têm de tomar uma decisão importante. Dos 18 homens entrevistados, 4 (22.2 \%) responderam que os familiares diretos residiam longe do local onde habitam. Já a questão "Com quantos familiares conversa todos os dias?" suscitou dúvidas e dificuldades de resposta, não conseguindo os entrevistados distinguir entre confiança, amizade e relações profundas. A cordialidade e a educação foram confundidas com laços profundos de amizade e companheirismo, pois consideravam que nos locais que frequentavam todos eram amigos.

A mobilidade, definida como movimento em todas as suas formas (desde a locomoção à utilização dos transportes), é fundamental para que os membros mais velhos da comunidade exerçam a sua participação (Anderson et al., 2014; Satariano et al., 2012). Uma das variáveis que mais influenciavam a participação dos homens inquiridos diz respeito ao meio de transporte preferencial para as suas deslocações. O exercício da participação era facilitado pela utilização de veículo próprio, por impulsionar os níveis de independência e de autonomia; contudo, apenas 7 inquiridos possuíam carro próprio e, destes, apenas 6 conduziam. Esta informação é um elemento a considerar na análise dos roteiros do dia a dia destes homens, no que concerne aos locais que frequentam e aos serviços a que recorrem, considerando que a opção entre recorrer a um ou outro serviço e entre deslocar-se ou não a determinado local estava dependente do meio de transporte utilizado.

Tal como constatado em diversos estudos (Ribeiro \& Paúl, 2012), a participação da população mais velha está dependente de variáveis que ultrapassam a esfera individual, estendendo-se às estruturas formais e informais. Na reflexão sobre as 18 entrevistas, é indubitável a importância da relação estabelecida entre a rede formal, constituída por profissionais qualificados, e a rede informal, composta pelos amigos e a família. Para os homens inquiridos, o apoio prestado pela família e os amigos na deslocação quotidiana é crucial para utilizarem os recursos ou serviços sociais, quer sob a forma de apoio 
direto na mobilidade/deslocação, quer através do acompanhamento no domicílio ou a respostas locais.

Através da análise dos mapas construídos a partir do ArcGIS, conseguimos verificar que as deslocações dos homens $80+$ inquiridos estão muito dependentes dos transportes públicos ou disponibilizados pelas associações ou familiares. Isto acontece sobretudo para as deslocações mais longas. As deslocações são mais frequentes no interior do município, sendo efetuadas em veículo próprio ou de familiares $(n=8 ; 44.4 \%)$, em transportes públicos $(n=5 ; 27.8 \%)$, mas maioritariamente a pé $(n=12$; $66.7 \%)$. As rotinas e a utilização de serviços ou recursos sociais realizam-se quotidianamente no interior da freguesia ou do município, procurando bens e serviços menos especializados, ou recorrendo à rede familiar. Por sua vez, a utilização de veículo próprio possibilita a procura de serviços especializados. Estes resultados de dependência do automóvel reforçam a importância da análise das transições de mobilidade dos indivíduos em idade avançada, nomeadamente a interrupção definitiva da condução, associada à diminuição da atividade, mobilidade/independência, aumento dos sintomas depressivos e limitações funcionais, essencialmente da função visual (MacLeod et al., 2014; Ragland et al., 2005). As formas de mobilidade são importantes para a capacidade de enfrentar desafios, caminhar, realizar atividades de lazer, tarefas diárias ou de socialização (Anderson et al., 2014; Satariano et al., 2012). Por sua vez, as restrições da mobilidade têm consequências na saúde e no bem-estar das pessoas mais velhas (Satariano et al., 2012).

Os mapas construídos a partir dos roteiros dos homens $80+$ entrevistados evidenciam sobretudo a dependência do automóvel e exibem dois perfis opostos de roteiros. O mapa representado na figura 1 corresponde a um perfil de homem que se desloca para lá dos limites da freguesia da sua área de residência, frequentando espaços e recursos nas diferentes freguesias do município de Odivelas. A distância por si percorrida é superior à da maioria dos inquiridos, bem como o número de recursos que utiliza: o transporte público e o automóvel particular para realizar as suas deslocações. Já o entrevistado representado no mapa da figura 2 corresponde a um perfil oposto, deslocando-se essencialmente no interior da freguesia, na sua área de residência, em trajetos curtos, num raio de 600 ou 800 metros. Os locais mais frequentados relacionam-se com o acesso aos cuidados médicos e ao banco. Habitualmente, os percursos são efetuados a pé ou de transporte público.

Figura 1 Mapa correspondente ao entrevistado n. ${ }^{\circ} 6$

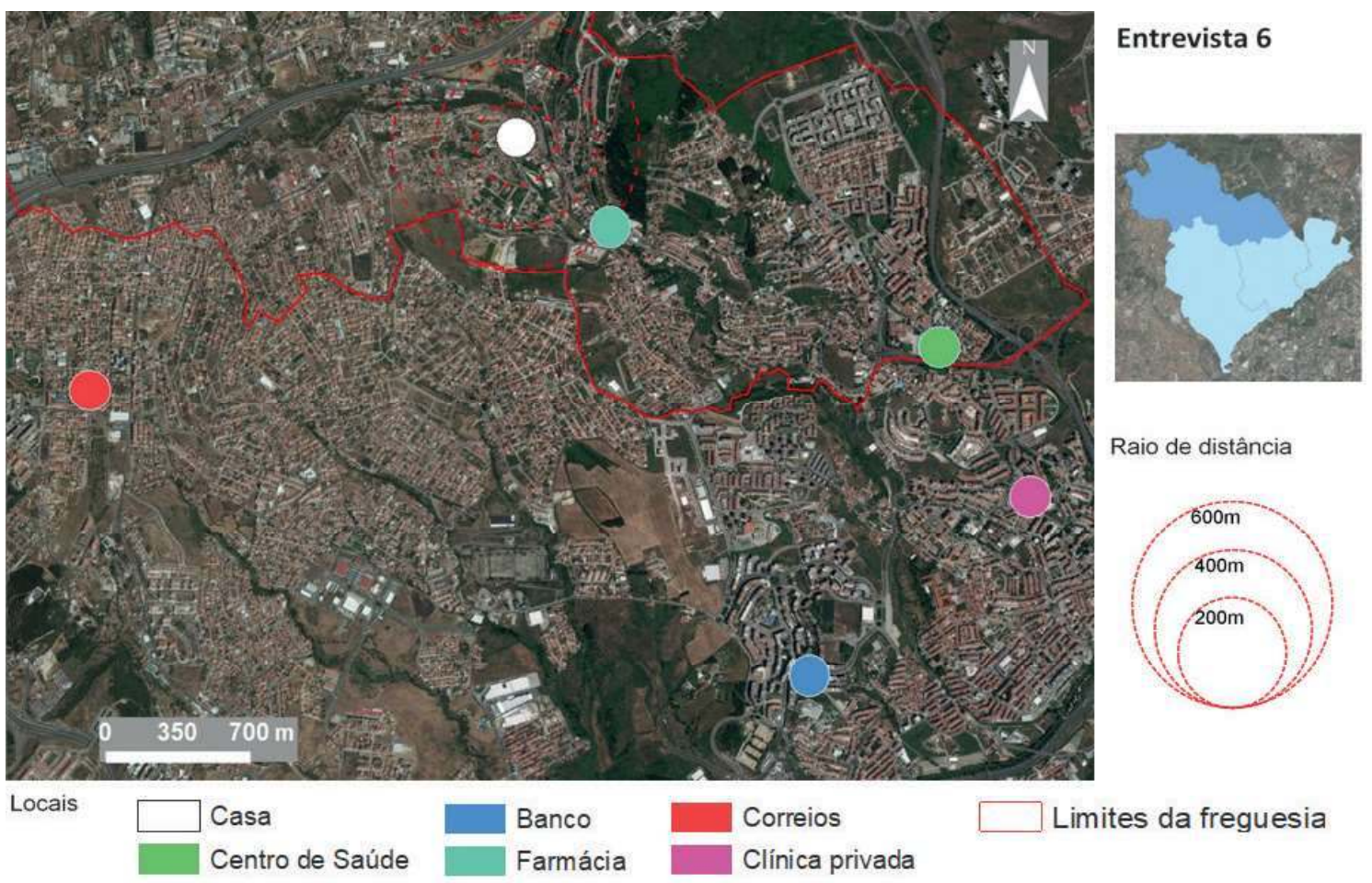

Escala (Base) 1:25000 
Figura $2 \triangleright$ Mapa correspondente ao entrevistado n. ${ }^{\circ} 11$

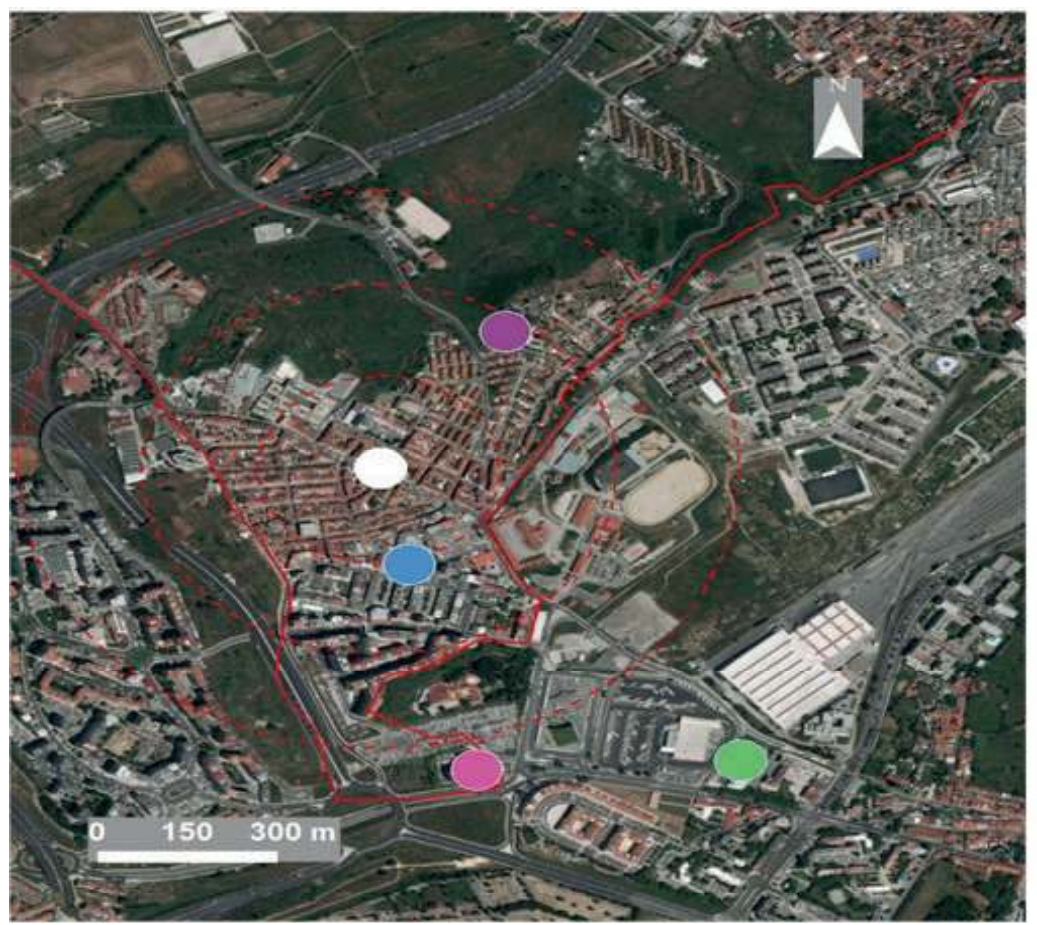

\author{
Entrevista 11 \\ Locais

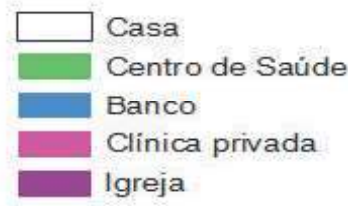 \\ $\square$ Limites da freguesia
}

Raio de distância

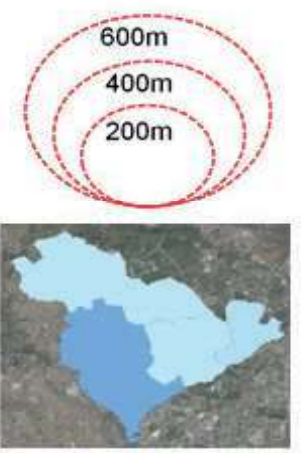

Escala (Base) 1:25000

A participação social dos homens inquiridos está condicionada pelos hábitos, rotinas, ocupação e condições ao longo do curso de vida. As maiores condicionantes são a saúde, as condições habitacionais e a falta de apoio formal/informal, por marcarem os níveis de autonomia e as rotinas nestas pessoas muito idosas. Outra dificuldade está relacionada com a deslocação e utilização de serviços de proximidade, podendo ser condicionada pelos níveis de autonomia. Podemos, assim, caracterizar estes homens em dois subgrupos populacionais: i) com autonomia, independência e possibilidade de utilização de veículo próprio; e ii) dependentes da família, amigos ou instituições, que disponibilizam o acesso a estes serviços, facilitando as deslocações quotidianas e permitindo uma escolha mais ampla de serviços e respostas sociais.

Inquiridos sobre "como ocupam os seus dias", os homens $80+$ passavam grande parte do seu tempo em casa, incluindo ao fim de semana. $\mathrm{Na}$ figura 3 podemos observar os locais mais frequentados, salientando-se a associação de reformados, os serviços de saúde e outros serviços essenciais. São estes os locais que compõem as rotinas diárias destes homens durante a semana. No período do fim de semana, visitam familiares ou recorrem a espaços públicos destinados a atividades de lazer, junto da sua área de residência.
Por entrevistarmos homens com idades tão avançadas, abordámos as expectativas pessoais, familiares e/ou a uma escala mais alargada para a sociedade. Quisemos saber o que ficou por fazer e identificar as suas ambições. Será que se sentem sobreviventes que ultrapassam a EV comum ao género masculino ou, por outro lado, revestem-se de solidão e vulnerabilidade? As entrevistas levam-nos a afirmar que a maioria dos homens inquiridos manifesta alguma descrença e desânimo com a sua vida. Poucos têm objetivos e expectativas individuais. A maioria apenas aguarda pelos últimos dias, pedindo saúde e alguma qualidade de vida para o futuro próximo. Preferem "pedir" algo para a sua família e afirmam ter cumprido tudo o que tinham planeado ao longo da vida. Os objetivos destes homens resumem-se a aguardar com tranquilidade pelos sonhos e ambições mais imediatos, sem expectativas a médio ou longo prazo. Focam-se sobretudo numa retrospetiva, através da lembrança das suas contribuições passadas para a sociedade e da ajuda que prestam aos seus familiares no presente, sob a forma de solidariedade: Emprestei dinheiro ao meu cunhado quando ficou desempregado, ainda ajudo os meus filhos quando precisam (entrevistado n. 3); A minha filha pede-me ajuda de vez em quando, é divorciada e precisou de pagar umas dívidas (entrevistado n. 15). 
Figura $3 \triangleright$ Locais frequentados pelos homens $80+$ entrevistados

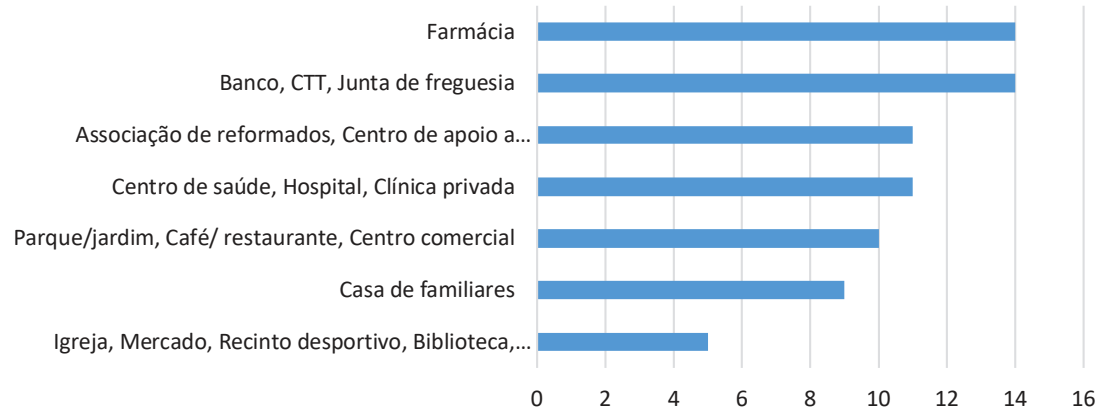

\section{Conclusão}

As características sociais e pessoais dos homens mais velhos entrevistados evidenciam implicações nos seus roteiros quotidianos, que se refletem em termos de participação e de ocupação. Foi possível identificar elementos facilitadores e inibidores desta participação.

A maioria dos indivíduos revelou baixos recursos pessoais e sociais, é caracterizada por baixa escolaridade, tem queixas/problemas de saúde, reside longe da família e é inativa. Estas condições limitam os seus percursos e a utilização dos espaços, levando os homens a recorrer apenas aos serviços sociais e de saúde essenciais. Como maiores condicionantes da participação social, autonomia e rotinas, destacam-se: i) fracas condições habitacionais/de habitabilidade; ii) condições de saúde deficientes; iii) ausência de apoio formal/informal; e iv) poucos recursos materiais/financeiros.

A estabilidade financeira e as boas condições socioeconómicas adquiridas ao longo da vida (associadas à escolaridade, à diferenciação profissional e ao acesso a serviços) são fatores que contribuem para uma maior longevidade (Fontes et al., 2013). Por sua vez, de acordo com os nossos resultados, as fracas condições socioeconómicas e os baixos níveis de escolaridade destes homens sobreviventes podem hipotecar a sua autonomia, o poder de decisão e os papéis sociais.

As condições associadas ao envelhecimento podem conduzir a um maior isolamento, originando a necessidade de procurar serviços mais especializados, que elevem a qualidade de vida e possibilitem as interações sociais com os seus pares (Quaresma, 2004). Estas considerações vão ao encontro dos nossos resultados, pois a grande maioria dos homens inquiridos passa a maior parte do seu tempo em casa e os seus relacionamentos sociais dependem sobretudo de associações.

Em concordância com estas fracas condições do envelhecimento no masculino, a maioria dos indivíduos entrevistados manifestou descrença e desânimo com a sua vida, bem como ausência de objetivos e expectativas. Ainda que se considerem satisfeitos com a relação que têm com os seus familiares/amigos, grande parte não tem a quem recorrer quando precisa de ajuda ou quanto tem de tomar uma decisão importante. Registam-se ainda preocupações, vivências antagónicas e sentimentos contraditórios, divididos entre a saudade da união familiar, o desejo do merecido descanso e o dever de ainda apoiar os familiares. Aguardando pelos seus últimos dias, estes homens desejam saúde e alguma qualidade de vida para um futuro a curto prazo. Envelhecer "bem" é envelhecer com saúde, sendo esta uma condição determinante para minimizar os impactos nefastos do envelhecimento, como as eventuais perdas de funcionalidade associadas à multimorbilidade e à doença crónica (Fernandes \& Burnay 2019).

A partir de determinadas idades, é notória a preocupação dos indivíduos no que diz respeito à proteção da sua saúde, exercendo um cuidado mais proativo e menos remediativo, que se traduz num aumento do número de anos vivido (Fernandes, 2008). No entanto, o estado de saúde nas classes etárias mais velhas depende não só do capital de saúde construído ao longo da vida, mas também dos recursos disponíveis (Fernandes \& Burnay 2019).

Também o meio de transporte que os homens $80+$ utilizam se revelou importante na determinação dos seus roteiros e serviços a que conseguem recorrer, privilegiando-se uma minoria que conduz e tem carro próprio. Este elemento remete para a urgência de respostas adequadas ao nível do planeamento urbano e da mobilidade dos mais velhos que se deslocam a pé ou de transportes públicos, com direito a frequentar espaços e serviços onde desenvolveram atividade e realizaram tarefas no decorrer da idade ativa. Estas orientações vão ao encontro de ações como a concretização de atributos da pedonalidade no estudo de Almeida (2016a) na cidade de Odivelas: o CIT-A-PE (walkable cities, cities for all people/cidades para todos os peões/ todas as pessoas). No seguimento da importância 
da mobilidade no exercício da participação em idades avançadas, Anderson et al. (2014) alerta para os benefícios de uma estrutura unificada, que examine o espectro de mobilidade em relação às ações individuais e às influências do ambiente. Esta estrutura permite avaliar os desafios e oportunidades de mobilidade das pessoas mais velhas e consiste na aplicação do modelo social ecológico (Anderson et al., 2014).

Os limites da participação cívica são mutáveis e difíceis de identificar, em parte devido à heterogeneidade que caracteriza as pessoas mais velhas, evidenciada por uma multiplicidade de funções, tarefas e projetos com os quais cada indivíduo se pode identificar (Almeida, 2016b). Para que a participação social seja plena, não podemos descurar a condição socioeconómica e a autonomia ou ainda elementos externos não controláveis pelos próprios, tais como a existência de projetos, diversificação de atividades e adequação dos espaços públicos (Bárrios, 2017). Por terem idades muito avançadas, os testemunhos destes homens revelam que é necessário um conjunto de elementos no que respeita a recursos pessoais e comunitários, reunidos num ecossistema que facilite o exercício da participação cívica, permitindo roteiros que acedam à utilização de serviços e respostas sociais locais e que preencham as necessidades.

\section{Notas}

1 Em relação a 2007, em 2018 a proporção de pessoas $65+$ aumentou $22.86 \%$ em Portugal, sendo um aumento superior ao da UE28, que foi de $15.88 \%$

2 Os dados do Eurostat registam em 2018 um aumento de $48.28 \%$ em Portugal e de $30.23 \%$ na UE28, em relação a 2007 .

3 Número de pessoas com 65 e mais anos por cada 100 pessoas menores de 15 anos.

4 Número de pessoas com 65 e mais anos por cada 100 pessoas em idade ativa (de 15 a 64 anos).

\section{Referências bibliográficas}

Almeida, M. F. (2016a). Age-friendly walkable urban spaces: A participatory assessment tool. Journal of Housing for the Elderly, 30(4), 396-411. https:// doi.org/10.1080/02763893.2016.1224791.

Almeida, M. F. (2016b). Iniciativas de participação cidadã de idosos em Portugal: Um estudo exploratório. Análise Social, 219(II), 402-431.

Anderson, L., Slonim, A., Yen, I., Jones, D., Allen, P., Hunter, R., Goins, R. T., Leith, K. H., Rosenberg, D., Satariano, W. A., \& McPhillips-Tangum, C. (2014). Developing a framework and priorities to promote mobility among older adults. Health Education \& Behavior, 41(1), 10-18. https://doi. org/10.1177/1090198114537492.
Bárrios, M. J. (2017). Políticas de envelhecimento ao nível local. Análise e avaliação de programas a partir do paradigma de envelhecimento ativo [Tese de doutoramento]. Instituto Superior de Ciências Sociais e Políticas da Universidade de Lisboa.

Bárrios, M. J., Fonseca, A., \& Fernandes, A. A. (2020). Ageing conditions of the Portuguese population, aged 50 years and over. The Journal of Aging and Social Change, 10(3), 9-21. https://doi. org/10.18848/2576-5310/CGP/v10i03/9-21.

Boom, D. E., Boersch-Supan, A., McGee, P., \& Seike, A. (2011). Population aging: Facts, challenges, and responses (PGDA Working Paper No. 7111). Program on the Global Demography of Aging.

Budib, M., Zulim, M.I., Marcon de Oliveira, V., \& Matos, V.T.G. (2020). Integrated continuous care: Collaborating with the elderly functionality. Biosci. J., 36(1), 266-275. http://dx.doi.org/10.14393/ BJ-v36n1a2020-42308.

Calado, D. F. (2004). Velhice: Solidão ou vida com sentido?. In M. L. Quaresma, A. A. Fernandes, D. F. Calado \& M. Pereira, O sentido das idades $d a$ vida. Interrogar a solidão e a dependência (pp. 51-72). Lisboa: Cesder Edições.

Daniel, F., Antunes, A., \& Amaral, I. (2015). Representações sociais da velhice. Análise Psicológica, 3(XXXIII), 291-30. https://doi.org/10.14417/ ap.972.

Daniel, F., Simões, T., \& Monteiro, R. (2012). Representações sociais do «envelhecer no masculino» e do «envelhecer no feminino». Ex AEquo, (26), 13-26.

Fernandes, A. A. (1997). Velhice e sociedade: Demografia, familia e políticas sociais em Portugal. Celta Editora.

Fernandes, A. A. (2004). Quando a vida é mais longa - Impactos sociais do aumento da longevidade. In M. L. Quaresma, A. A. Fernandes, D. F. Calado \& M. Pereira, O sentido das idades da vida. Interrogar a solidão e a dependência (pp. 13-36). Cesder Edições.

Fernandes, A. A. (2008). Questões demográficas. Demografia e sociologia da população. Edições Colibri.

Fernandes, A. A. (2016). A proteção social na velhice estará em risco?. In A. A. Fernandes, P. C. Albuquerque \& A. M. Fonseca (Eds.), A (re)forma das reformas. Uma análise sociológica, económica e psicológica da reforma e do sistema de pensões (pp. 9-53). Almedina.

Fernandes, A. A., \& Botelho, M. (2007). Envelhecer activo, envelhecer saudável: $\mathrm{O}$ grande desafio. Fórum Sociológico, (17), 11-16.

Fernandes, A. A., \& Burnay, R. (2019). Homens saudáveis, mulheres doentes? Um estudo sobre a esperança de vida e a saúde da população portuguesa. Revista Brasileira de Pesquisa em Saúde, 21(2), 17-28.

Fernandes, A. A., Burnay, R., Gomes, I., Gil, A. P., Marques, A. M., \& Botelho, M. A. (2012). Envelhecimento e saúde: Uma análise de género [Aging and health: A gender analysis]. Final Report. (PTDC/CS- 
-SOC/103608/2008). CESNOVA-FCSH/UNL, FCT. https://doi.org/10.13140/RG.2.2.22077.87526.

Fernandes, A., Mateus, C., \& Perelman, J. (2009). Health and health care in Portugal: Does gender matter?. Instituto Nacional de Saúde Ricardo Jorge (INSA).

Figueiredo, M., Tyrrel, M., Carvalho, C., Luz, M., Amorim, F., \& Loiola, N. (2007). As diferenças de género na velhice. Revista Brasileira de Enfermagem, 60(4), 422-427.

Fontes, A. P., Botelho, M. A., \& Fernandes, A. A. (2013). A funcionalidade dos mais idosos ( $\geq 75$ anos): Conceitos, perfis e oportunidades de um grupo heterogêneo. Rev. Bras. Geriatr. Geronto, /16(1), 91-107.

ILC-BR. (2015). Active ageing: A policy framework in response to the longevity revolution (1st ed.). International Longevity Centre Brazil.

Iversen, T. N., Larsen, L., \& Solem, P. E. (2009). A conceptual analysis of ageism. Nordic Psychology, 61(3), 4-22. https://doi.org/10.1027/19012276.61.3.4.

Lopes, P. (2004). Qualidade de vida e suporte social do idoso no meio rural e no meio urbano: Um estudo comparativo e correlacional (Dissertação de Mestrado). ISPA.

Machado, P. (2007). Reflectindo sobre o conceito de envelhecimento activo, pensando no envelhecimento em meio urbano. Forum Sociológico, (17), 53-63. https://doi.org/10.4000/sociologico.1646.

MacLeod, K. E., Satariano, W. A., \& Ragland, D. R. (2014). The impact of health problems on driving status among older adults. J Transp Health, 1(2), 86-94. https://doi.org/10.1016/j.jth.2014.03.001.

Pereira, M. (2004). Isolamento e resiliência. In M. L. Quaresma, A. A. Fernandes, D. F. Calado \& M. Pereira (Eds.), O sentido das idades da vida. Interrogar a solidão e a dependência (pp. 83-102). Cesder Edições.

Pimentel, L. (2001). O lugar do idoso na família: Contextos e trajectórias. Quarteto Editora.
Pinto, C. (2012). Representações e práticas do empowerment nos trabalhadores sociais (Tese de doutoramento). Instituto Superior de Ciências Sociais e Políticas da Universidade de Lisboa.

Quaresma, M. L. (2004). Preâmbulo. In M. L. Quaresma, A. A. Fernandes, D. F. Calado \& M. Pereira (Eds. ), O sentido das idades da vida. Interrogar a solidão e a dependência (pp. 3-12). Cesder Edições.

Ragland, D. R., Satariano, W. A., \& MacLeod, K. E. (2005). Driving cessation and increased depressive symptoms. J Gerontol A Biol Sci Med Sci., 60(3), 399-403.

Ribeiro, O., \& Paúl, C. (2011). Manual de envelhecimento ativo. Lidel.

Satariano, W. A., Guralnik, J. M., Jackson, R. J., Marottoli, R. A., Phelan, E. A., \& Prohaska, T. R. (2012). Mobility and aging: New directions for public health action. American Journal of Public Health, 102(8), 1508-1515. https://doi. org/10.2105/AJPH.2011.30063.

Satariano, W. A., Ivey, S. L., Kurtovich, E., Kealey, M., Hubbard, A., Bayles, C. M., Bryant, L. L., Hunter, R. H., \& Prohaska, T. R. (2010). Lower-body function, neighborhoods and walking in an older population. American Journal of Preventive Medicine, 38(4), 419-428. https://doi.org/10.1016/j. amepre.2009.12.031.

Waite, L. J. (2004). Aging, health, and public policy: Demographic and economic perspectives, population and development review. Population Council.

Walker, A. (2002). Ageing in Europe: Policies in harmony or discord?. International Journal of Epidemiology, 31(4), 758-761. https://doi.org/10.1093/ ije/31.4.758.

WHO. (2002). Active ageing - A policy framework. World Health Organization.

WHO. (2007). Global age-friendly cities: A guide. World Health Organization.

Maria João Bárrios. Universidade de Lisboa, Instituto Superior de Ciências Sociais e Políticas, Centro de Administração e Políticas Públicas, Lisboa, Portugal. Email: mbarrios@iscsp.ulisboa.pt

Cláudio Faustino. Investigador independente, Portugal. Email: claudio_Faustino16@hotmail.com 